\title{
Extensão Popular: uma proposta transformadora para a educação superior
} Popular Extension: a transformer proposal for higher education

\author{
Dirceu Benincá \\ Doutor em Ciências Sociais e Pós-Doutor em Educação. \\ Professor da Universidade Federal do Sul da Bahia (UFSB) \\ Campus Paulo Freire - Teixeira de Freitas/BA \\ dirceuben@gmail.com
}

Fernando Silva Campos

Estudante do Bacharelado Interdisciplinar em Saúde Universidade Federal do Sul da Bahia (UFSB) Campus Paulo Freire - Teixeira de Freitas/BA fernandoscampos@hotmail.com

Resumo: A extensão é um importante espaço de diálogo, de troca de conhecimentos, integração e construção de possibilidades diversas entre a universidade e a sociedade. Trata-se de uma dimensão fundamental da instituição universitária, por meio da qual esta pode aprender com os saberes populares e também oferecer contribuições significativas diante das múltiplas questões do mundo moderno. O presente artigo objetiva fazer uma revisão bibliográfica acerca da extensão universitária e sua perspectiva popular. Visa, ainda, apresentar desafios para a consolidação da extensão popular na Universidade Federal do Sul da Bahia (UFSB), a partir da valorização dos conhecimentos da população, buscando o desenvolvimento cultural e social da comunidade regional.

Palavras-chave: universidade popular; extensão popular; democratização de saberes; desenvolvimento regional.

Abstract: Extension is an important space for dialogue, exchange of knowledge, integration and construction of diverse possibilities between the university and society. It is a fundamental dimension of the university institution through which it can learn from popular knowledge and also offer meaningful contributions to the multiple issues of the modern world. This article aims to make a bibliographical review about university extension and its popular perspective. It also aims to present challenges for the consolidation of the popular extension at the Federal University of Southern Bahia (UFSB), based on the valorization of the knowledge of the population, seeking the cultural and social development of the regional community.

Keywords: popular university; popular extension; democratization of knowledge; regional development. 


\section{Introdução}

A extensão popular surge como uma proposta integrativa e democrática, que busca valorizar o conhecimento popular e inseri-lo no campo frutuoso da reflexão. A dimensão popular da extensão não inferioriza sua qualidade crítica e acadêmica. O "ser popular" a identifica com propostas e ações comprometidas com o protagonismo e a cidadania das classes populares, valorizando a "leitura do mundo", predecessora importante da "leitura da palavra" (FREIRE, 1996. p. 32).

A extensão popular procura contemplar realidades constantemente negligenciadas pelo "olhar geral", seja a pobreza, a violência, as carências educacionais, a poluição, a exploração do trabalho, a terra, a alimentação e outros. Sem a interação dialógica permitida pela extensão, a universidade corre o risco de ficar isolada e deslocada dos problemas sociais, tornando-se incapaz de oferecer contribuições à sociedade por meio do conhecimento, das inovações tecnológicas e dos profissionais que o desenvolvimento requer (FORPROEX, 2012).

No que tange a este aspecto da educação superior, a Universidade Federal do Sul da Bahia (UFSB) revela seu compromisso de popularizar a extensão sem vulgarizá-la, ou seja, democratizá-la com qualidade e competência. Juntamente com outras instituições de proposta social, a UFSB procura contribuir de modo significativo com a reversão das injustiças, das desigualdades sociais e do crescimento predatório e excludente. De acordo com seu Plano Orientador ${ }^{1}$, o conhecimento é um importante vetor de desenvolvimento humano e o principal valor econômico da contemporaneidade.

Um dos grandes desafios da UFSB é valorizar as práticas e saberes das comunidades locais, sem perder de vista as questões mais amplas que acontecem no mundo contemporâneo, marcado pela complexidade e por crises diversas (BENINCÁ; PEREIRA, 2016). Entretanto, para que esta meta seja alcançada, é necessário um financiamento adequado por parte do Estado, de modo a garantir o exercício pleno de suas atividades-fim (extensão, ensino e pesquisa), possibilitando a acessibilidade e a permanência estudantil e colaborando com o empoderamento dos grupos socialmente marginalizados. 


\section{A emergência da extensão universitária}

O termo "extensão" possui variadas compreensões. Etimologicamente, significa o "ato de estender algo a alguém". A extensão teve sua origem nos primórdios da prática universitária (ROCHA apud SERRANO, 2013), mas foi a partir do século XIX que ela se afirmou decisivamente como um dos pilares do tripé da universidade. Esta dimensão acadêmica teve forte expressão no contexto da Revolução Industrial europeia e no desenvolvimento econômico dos Estados Unidos. A princípio, foram delineados dois modelos de extensão: o inglês, mais social e que se opunha às contradições capitalistas; e o norte-americano, de cunho mais econômico e que buscava transferir tecnologia para a produção industrial (IMPERATORE et alii, 2015).

No contexto da América Latina, as revoluções Mexicana e Cubana e o Movimento Estudantil de Córdoba colaboraram decisivamente no delineamento da concepção extensionista da universidade. Esses movimentos manifestaramse contrários ao distanciamento universitário dos problemas da sociedade e ao elitismo acadêmico. O extensionismo latino-americano acompanhou o percurso emancipador do continente e suas lutas para desvencilhar-se do jugo colonialista europeu. Com isso, o foco dos estudos e reflexões acadêmicos foi recaindo progressivamente sobre as realidades do contexto local, suas manifestações culturais, históricas e suas lutas pela libertação do povo oprimido.

A reforma universitária no Brasil, nos anos 1930, regulamentou o Estatuto das Universidades Brasileiras e definiu a extensão a partir de seus objetivos. O Decreto 19.851, de 11 de abril de 1931, no artigo 42, afirma: "A extensão universitária será efetivada por meio de cursos e conferências de caráter educacional ou utilitário, uns e outras organizados pelos diversos institutos da Universidade, com prévia autorização do Conselho Universitário”.

O parágrafo $1^{\circ}$ do artigo citado define: "Os cursos e conferências, de que trata este artigo, destinam-se principalmente à difusão de conhecimentos úteis à vida individual ou coletiva, à solução de problemas sociais ou à propagação de ideias e princípios que salvaguardem os altos interesses nacionais”. O artigo 109 acrescenta que a "extensão universitária destina-se à difusão de conhecimentos filosóficos, artísticos, literários e científicos em benefício do aperfeiçoamento individual e coletivo". 
Em sua fase inicial, a extensão universitária no Brasil restringiu-se ao espaço acadêmico. Limitava-se a reflexões teóricas, sem comprometimento direto com os problemas sociais. O saber era adquirido a partir de uma visão contemplativa e transmitido de modo unidirecional, corroborando com a concepção socrática de que o conhecimento do bem é o meio necessário para uma vida virtuosa e uma ação justa.

De acordo com Serrano (2013), a extensão universitária brasileira sofreu mudanças conceituais com o passar do tempo, sendo possível identificar ao menos quatro momentos expressivos dessa transformação:

a) Extensão entendida como transmissão vertical e messiânica do conhecimento: inserida no perfil autoritário da universidade e alheia à cultura e saberes populares. Segundo Freire (2006, p. 22), "estes termos envolvem ações que, transformando o homem em quase 'coisa' negam-no como um ser de transformação do mundo".

A extensão vertical reforça o caráter elitista da educação superior e agrava ainda mais as desigualdades sociais. Acaba por legitimar o contraste das condições existente entre a restrita parcela populacional que tem acesso ao ensino superior e a grande maioria que é privada dele. De acordo com Maciel (1963, p. 25-26), esta multidão fica "isolada na mais completa cegueira espiritual e embrutecida no abandono de uma forma de escravização social e econômica", submissa à massificação da mídia e conduzida pelos ditames do consumismo e da moda fugaz.

b) Extensão como voluntarismo: manifestou-se como um instrumento de mudança na atuação das universidades. Interpelou a relação destas com a sociedade e manifestou o profundo questionamento acerca das práticas acadêmicas, muitas vezes dissociadas dos problemas sociais. Nesse sentido, Rocha (apud SERRANO, 2013) aponta os seguintes exemplos: as ações educativas desenvolvidas pelos jesuítas no período da colonização americana; o extensionismo rural nos Estados Unidos e o movimento estudantil latino-americano, especialmente o Movimento Estudantil de Córdoba/ Argentina (1918). O extensionismo voluntarista busca um maior comprometimento com a realidade da população. Contudo, apesar de sua 
importância, ele se limita a cuidados paliativos e não interfere diretamente nas causas profundas das desigualdades.

c) Extensão como ação sociocomunitária: movimento desvinculado das universidades, surgido no contexto das ditaduras latino-americanas e do regime militar no Brasil. Constituiu-se como uma ação não sistemática, em que os estudantes não estabeleciam vínculos permanentes com os locais onde atuavam. Alguns exemplos são: os Centros Rurais de Treinamento e Ação Comunitária (CRUTAC) e o Projeto Rondon (IMPERATORE et alii, 2015). “Tais projetos contrapunham-se à extensão universitária crítica e socialmente comprometida retomando uma prática conservadora e meramente assistencialista" (SERRANO, 2013, p. 9).

d) Extensão enquanto dimensão acadêmico-institucional: sob essa perspectiva, a extensão é entendida como um processo educativo e científico. "Ao fazer extensão estamos produzindo conhecimento, um conhecimento transformador que correlaciona a universidade e a sociedade" (SERRANO, 2013, p. 11). Este conceito apresenta uma extensão universitária democrática, interdisciplinar e integrada com a realidade sociocultural da comunidade.

\section{Viragens teóricas e práticas da extensão}

No Brasil, os anos 1960 marcam o início de importantes viragens teóricas e práticas no campo da extensão universitária. Nesse sentido, merece destaque a atuação de Paulo Freire que deu início ao Serviço de Extensão Social, no Recife, com o objetivo de trazer a extensão universitária para o contexto da sociedade. Tal movimento foi reprimido pelo regime da ditadura militar, instaurado pouco tempo depois. Os anos 1980 foram marcados pela aproximação da extensão com os movimentos sociais e, nas décadas seguintes, foi sendo delineada a construção de uma nova política de extensão no Brasil, baseada na concepção freiriana de via de mão dupla (MELO-NETO, 2003).

A criação do Fórum Nacional de Pró-Reitores de Extensão das Universidades Públicas Brasileiras, em 1987, permitiu uma maior discussão e avanços na prática 
extensionista. Esse Fórum definiu a extensão como "o processo educativo, cultural e científico que articula o ensino e a pesquisa de forma indissociável e viabiliza a relação transformadora entre a Universidade e a Sociedade" (FORPROEX, 1987). A extensão é inserida no campo acadêmico, sendo apresentada como um meio democrático e transformador que possibilita visão ampla e integrada da realidade social.

A Constituição Federal de 1988 representou um avanço estrutural nessa trajetória, ao reconhecer a extensão como um dos pilares inseparáveis da prática universitária brasileira, juntamente com o ensino e a pesquisa. Segundo Marilena Chauí (2003, p. 5), "a universidade exprime a estrutura e o modo de funcionamento da sociedade como um todo". O reconhecimento constitucional manifesta a importância e o significado da prática extensionista e a chancela como um instrumento de transformação social e crescimento participativo.

Serrano (2013) afirma que nas últimas duas décadas muitas mudanças têm ocorrido na práxis pedagógica das universidades brasileiras e, assim, colaborado para repensar a dimensão formativa da extensão universitária. Essas mudanças podem ser percebidas no novo conceito de sala de aula, na inserção de estágios durante os cursos, na preocupação com a ampliação do acesso e democratização do saber, na formação cidadã dos estudantes etc. O Plano Nacional de Extensão Universitária, elaborado em 1998, procurou ressignificar a extensão numa perspectiva cidadã, reafirmando-a como processo acadêmico indispensável e assegurando a relação bidirecional entre a universidade e a sociedade.

O Plano Nacional de Educação (PNE 2014 - 2024), em sua estratégia 12.7 determina que as universidades devem "assegurar, no mínimo, 10\% (dez por cento) do total de créditos curriculares exigidos para a graduação em programas e projetos de extensão universitária, orientando sua ação, prioritariamente, para áreas de grande pertinência social". Essa meta identifica na extensão um importante elemento construtor do conhecimento e promove nos estudantes a possibilidade de transformação social. Ela traduz um novo modo de pensar a missão universitária e atribui a cada um de seus membros a capacidade de formar um mundo mais humano e solidário.

A partir da reabertura política no Brasil, a universidade passou a ser discutida em seu caráter público e estatal, devendo engajar-se com a população menos favorecida. Sob essa perspectiva, a extensão é entendida como um meio da universidade cumprir sua função social (NOGUEIRA, 2001), destacando-se, nesse 
momento, vários projetos no campo da educação de jovens e adultos e atividades sociais em regiões mais desassistidas pelas políticas públicas.

Boaventura de Sousa Santos (2005b) defende que a extensão não pode ser orientada para atividades rentáveis, com o intuito de arrecadar fundos para a instituição, evitando assim sua privatização. Pelo contrário, suas ações devem prestar apoio solidário na solução dos problemas da exclusão e discriminação sociais, dando voz aos grupos excluídos e discriminados. Segundo ele, a extensão universitária não pode representar uma invasão cultural com atitudes imperialistas e dominadoras. Deve, ao contrário, constituir-se em um processo democrático, colaborativo, autenticamente dialógico (FREIRE, 1983, p. 28) e reconhecedor do "outro" enquanto ser humano e sujeito de direitos.

A sensibilidade às demandas sociais é um dos princípios básicos da extensão universitária participativa, como assinala Thiollent (2000, p. 20, 21 e 23):

Devido a sua maior abertura e sensibilidade às demandas sociais e locais, a extensão facilita as iniciativas conjuntas universidade/ atores externos [...]. É desejável que a extensão seja orientada em função de princípios metodológicos participativos, no intuito de estimular a cooperação, o comprometimento e a solidariedade entre as partes interessadas [. . .]. Por sua vez, a metodologia participativa capacita os atores, implicando-os na construção do projeto e no seu desenrolar. Criam-se também condições que possibilitam a melhor interação entre participantes de camadas populares e da universidade.

Apesar de ser uma proposta transformadora, a extensão popular não pode pretender substituir a ação do poder público. Requer, isto sim, que esteja articulada com a comunidade e que se constitua como um espaço de fortalecimento da consciência crítica e de exercício da democracia. Significa dizer que a extensão universitária, assim concebida, estimula ao enfrentamento/superação de situações-problemas e à luta pela cidadania ativa.

Portanto, fazer extensão é agir pró-ativamente, no sentido de superar desigualdades, valorizar o diferente e buscar novos caminhos para a educação e para a própria sociedade como um todo. Por meio dela, muitas barreiras podem ser 
superadas e novas conexões criadas, colaborando na emancipação dos sujeitos e promovendo um ambiente de maior solidariedade e cooperação.

\section{A extensão na Universidade Popular}

Em se tratando de instituições universitárias que se pretendem populares na sua proposta de atuação, como é o caso da Universidade Federal do Sul da Bahia (UFSB), a extensão adquire uma centralidade e significado ainda maiores. A realidade socioeconômica, sociopolítica, sociocultural e ambiental da região onde esta se encontra situada, suscita múltiplos e urgentes desafios para a extensão.

Para essa abordagem, é adequado o conceito da "ecologia de saberes" utilizado por Santos (2005a, p. 76) que, segundo ele, significa "a extensão universitária ao contrário”. Esta consiste na abertura da universidade para aprender com as práticas sociais, nomeadamente com os camponeses, os indígenas, os afrodescendentes, os ribeirinhos, as mulheres, enfim, as camadas populares. Para Ribeiro (2009), a extensão popular exige uma reformulação de conceitos, que superam o ensino técnico:

A percepção quanto à importância da participação na organização comunitária nos faz reconhecer a insuficiência da intervenção técnica e a necessidade de contribuirmos com a luta pelos direitos básicos desses sujeitos, como forma de garantir condições mínimas de saúde. Sendo assim, o trabalho na extensão universitária na perspectiva de EP (Extensão Popular) requer uma reformulação de conceitos e de reorientação de prática, o que vai se instituindo no decorrer do aprendizado (RIBEIRO, 2009, p. 342).

Desse modo, a extensão no âmbito da Universidade Popular precisa traduzirse em ação a partir das demandas e saberes da sociedade articulados com o conhecimento científico construído pela universidade (BENINCÁ, 2011). Necessita colaborar com a vida da comunidade, superando o assistencialismo e/ou a mera prestação de serviços. Por meio da extensão, muitas realidades podem ser transformadas na área social, da educação, da saúde, da arte, do meio ambiente etc. 
O caráter popular leva a extensão a ultrapassar a perspectiva das "empresas juniores" e das assessorias especializadas, para dirigir-se às periferias geográficas e existenciais e aos locais desassistidos pelas políticas públicas. A extensão tem, pois, um compromisso indispensável, intransferível e inadiável para com a maioria da população brasileira que, historicamente, permaneceu excluída dos benefícios sociais e é constantemente criminalizada pelos grandes meios de comunicação e alijada de seus direitos.

Santos (2008) denomina a realidade da exclusão social como sociologia das ausências. Com esse conceito, alude aos saberes usurpados dos povos colonizados, o que representa uma irreparável injustiça social e cognitiva. Segundo ele, essas injustiças precisam ser enfrentadas com ações emancipatórias (sociologia das emergências), onde os sujeitos sociais atuem de modo coletivo e articulado, gerando, assim, novas perspectivas de futuro.

O sul da Bahia constitui locus por excelência da sociologia das ausências desde o fatídico "descobrimento" do Brasil. Uma parcela significativa da população continua explorada pela elite agrária e comercial da região, com poucos direitos garantidos e sujeita à massificação cultural. Existem muitos latifúndios ao lado de comunidades indígenas e quilombolas despossuídas e sem a devida assistência do Estado. Associa-se a esse quadro, ecossistemas em constante degradação, alta ocupação territorial por monoculturas (sobretudo de eucalipto) e pecuária; elevadas taxas de desemprego e subemprego, bem como de evasão escolar.

De outra parte, verifica-se enorme potencial natural e cultural na região. É nesse contexto que a sociologia das emergências necessita ser fortalecida. Para tanto, a Universidade Federal do Sul da Bahia adquire papel importante e já tem debatido amplamente diversas formas de promover o desenvolvimento integral e integrado. A participação em Comitês de Bacias Hidrográficas; a organização conjunta de eventos como a $68^{\text {a }}$ Reunião da Sociedade Brasileira para o Progresso da Ciência (SBPC) e a V Jornada de Agroecologia da Bahia; a realização do I Fórum Social da UFSB; a atuação efetiva do Conselho Estratégico Social; as diversas ações coordenadas pela Pró-reitora de Sustentabilidade e Integração Social; a mesa redonda sobre produção agroecológica em assentamentos (com membros do MST do Sul da Bahia) são alguns exemplos da seriedade com que a universidade assume a extensão dentro de uma perspectiva inter e transdisciplinar.

Em seus debates, a instituição defende a importância de promover o caráter híbrido da extensão, onde a sociedade é auscultada atentamente, de modo a 
identificar os problemas concretos e, assim, envolver os estudantes, os docentes e o corpo técnico em um grande e permanente processo de ensino-aprendizagemação. A ênfase na dimensão popular propugna por desburocratizar a extensão e garantir uma efetiva integração social. Partindo da compreensão de que a extensão é uma dimensão que deve perpassar o conjunto das ações, dos projetos e dos programas da universidade - e não ser encerrada em uma "caixinha" - a instituição optou por não criar uma Pró-reitora de Extensão.

No que diz respeito à concepção política da extensão na UFSB, torna-se necessário potencializar a ecologia dos saberes e fazeres, numa via de mão dupla entre a universidade e as Organizações Não Governamentais (ONGs), os movimentos sociais e culturais, as comunidades, as associações e todas as forças vivas e setores da sociedade. Desse modo, fortalece-se a possibilidade de desenvolver ações significativas e transformadoras. Trata-se de dar maior ênfase à extensão, devidamente associada com o ensino e a pesquisa, desde uma visão crítica e criativa da realidade. Essa concepção aponta para uma noção de extensão intensa.

\section{Considerações finais}

Muitas universidades brasileiras estão investindo significativamente em novas metodologias de ensino, pesquisa e extensão. Além das mudanças curriculares, buscam novas referências epistemológicas e didáticas para integrar o conhecimento acadêmico com a realidade social. Entre outras, destaca-se a extensão popular como uma forma de dialogar com a sociedade e potencializar aprendizagens e fazeres conjuntos.

Apesar de ter suas bases históricas na década de 1960, com Paulo Freire, a extensão popular é uma proposta inovadora e com grande poder de mobilização político-pedagógica e social. Concretamente, ela pode colaborar a fim de que os sujeitos oprimidos e excluídos adquiram uma consciência mais crítica, se mobilizem em face de seus direitos e se empenhem na construção de uma sociedade mais justa e equânime.

Promover a agroecologia, a economia solidária, o consumo consciente, as adequadas ações do pós-consumo (reciclagem, reutilização, compostagem etc.); fortalecer a saúde preventiva e coletiva, a organização de cooperativas e associações; estimular o planejamento de cidades educadoras, saudáveis e susten- 
táveis; desencadear a articulação dialógica e virtuosa com os movimentos sociais populares, com as comunidades tradicionais. Essas e muitas outras práticas se constituem em compromissos de primeira grandeza para a extensão popular de que, pelo descrito, a UFSB não poderá e não deverá se furtar de investir todas as forças disponíveis.

\section{Nota}

1 Disponível em: <http://ufsb.edu.br/wp-content/uploads/2015/05/Plano-Orientador-UFSBFinal1.pdf>. Acesso em: 20 mar. 2017.

\section{Referências}

BENINCÁ, Dirceu; PEREIRA, Thiago Ingrassia. Universidade popular e a construção do inédito viável - o caso da UFFS. In: DEL VECCHIO, Angelo; SANTOS, José Eduardo de Oliveira (Orgs.), Educação superior no Brasil: modelos e missões institucionais. São Paulo: BT Acadêmica, 2016, p. 121-145.

BENINCÁ, Dirceu. Uma universidade em movimento. In: BENINCÁ, Dirceu (Org.). Universidade e suas fronteiras. São Paulo: Outras Expressões, 2011, p. 31-63.

CHAUÍ, Marilena. A universidade pública sob nova perspectiva. Revista Brasileira de Educação, v. 24, p. 5-15, Set/Out/Nov /Dez 2003.

FÓRUM DE PRÓ-REITORES DE EXTENSÃO DAS INSTITUIÇÕES PÚBLICAS DE EDUCAÇÃO SUPERIOR BRASILEIRAS . Plano Nacional de Extensão Universitária. Manaus, AM, mai. 2012. Disponível em: < https://www.ufmg.br/proex/renex/documentos/2012-07-13-PoliticaNacional-de-Extensao.pdf $>$ Acesso em: 05 nov. 2016.

FÓRUM DE PRÓ-REITORES DE EXTENSÃO DAS INSTITUIÇÕES PÚBLICAS DE EDUCAÇÃO SUPERIOR BRASILEIRAS, 1987. Coleção Extensão Universitária FORPROEX, vol. I. Disponível em: <http://www.renex.org.br/documentos/Colecao-Extensao-Universitaria/01Plano-Nacional-Extensao/Plano-nacional-de-extensao-universitaria-editado.pdf $>$. Acesso em: 05 nov. 2016.

FREIRE, Paulo. Pedagogia da autonomia: saberes necessários à prática educativa. 34. ed., São Paulo: Paz e Terra, 2006.

Extensão ou comunicação? 7. ed., Rio de Janeiro: Paz e Terra, 1983. 
IMPERATORE, Simone Loureiro Brum; PEDDE, Valdir; IMPERATORE, Jorge Luis Ribeiro. Curricularizar a extensão ou extensionalizar o currículo? Aportes teóricos e práticas de integração curricular da extensão ante a estratégia 12.7 do PNE. In: COLÓQUIO INTERNACIONAL DE GESTÃO UNIVERSITÁRIA, 2015, Argentina. Disponível em: < https:// repositorio.ufsc.br/bitstream/handle/123456789/136064/101_00175.pdf?sequence=1> Acesso em: 06 nov. 2016.

MACIEL, Jarbas. A fundamentação teórica do sistema Paulo Freire. Revista de Cultura da Universidade do Recife. Recife, n. 4, p. 25-8, abr./jun. 1963.

MELO NETO, Francisco José de. Extensão universitária e produção do conhecimento. Conceitos, v. 5, n. 8, p. 13-9, 2003. Disponível em: <http://www.prac.ufpb.br/copac/extelar/ producao_academica/artigos/pa_a_ext_prod_conhecimento.pdf $>$. Acesso em: 14 nov. 2016.

NOGUEIRA, Maria das Dores Pimentel. Extensão universitária no Brasil: uma revisão conceitual. In. FARIA, D. S. (Org.). Construção Conceitual da Extensão na América Latina. Brasília: Editora UNB, 2001. p. 57-72.

RIBEIRO, Kátia Suely Queiroz Silva. A experiência na extensão popular e a formação acadêmica em fisioterapia. Cadernos Cedes. Campinas, SP, v. 29, n. 79, p. 335-346, set./dez. 2009. Disponível em: < http://www.scielo.br/pdf/ccedes/v29n79/04.pdf>. Acesso em: 07 nov. 2016.

SANTOS, Boaventura de Sousa. A gramática do tempo: para uma nova cultura política. 2 . ed., São Paulo: Cortez, 2008.

. A universidade no século XXI: para uma reforma democrática e emancipatória da Universidade. 2. ed., São Paulo: Cortez, 2005a.

. A justiça social vai obrigar a que se comprometa com a justiça cognitiva.

Diversa Cidadania, Revista da Universidade Federal de Minas Gerais, Ano 3, n 8, outubro de 2005b. Disponível em: <https://www.ufmg.br/diversa/8/entrevista.htm>. Acesso em: 19 nov. 2016.

SERRANO, Rossana Maria Souto Maior. Conceitos de extensão universitária: um diálogo com Paulo Freire. Grupo de Pesquisa em Extensão Popular, 2013. Disponível em: < http:// www. prac. ufpb. br/copac/extelar/atividades/discussao/artigos/conceitos_de_extensao_ universit aria. pdf>. Acesso em: 13 nov. 2016.

THIOLLENT, Michel. A metodologia participativa e sua aplicação em projetos de extensão universitária. In: THIOLLENT, M.; ARAÚJO FILHO, T.; SOARES, R. L. S. (Org.). Metodologia e experiências em projetos de extensão. Niterói/RJ: EdUFF, 2000.

recebido em 21 mar. 2017 / aprovado em 11 set. 2017

Para referenciar este texto:

BENINCÁ, D.; CAMPOS. F. S. Extensão Popular: uma proposta transformadora para a educação superior. Dialogia, São Paulo, n. 27, p. 145-156, set./dez. 2017. 